\title{
TEORIAS DE INVESTIMENTO: UMA LEITURA PRELIMINAR, A PARTIR DOS PÓS KEYNESIANOS E KALECKIANOS ${ }^{1}$
}

\author{
Jonilson Figueredo ${ }^{2}$ \\ Suzete Câmara ${ }^{3}$
}

\section{Resumo}

Refletindo a importância do investimento no debate macroeconômico, o presente ensaio propõe uma análise preliminar dos determinantes das decisões de investimento privado em duas vertentes da heterodoxia: os pós-keynesianos e os kaleckianos. Utilizando uma metodologia estritamente bibliográfica, e sob a justificativa da demanda pelo debate do tema nos espaços acadêmico e político-econômico, questiona: há diferenças significativas, do ponto de vista teórico, entre os dois modelos? Mesmo sendo orientados pelo Princípio da Demanda Efetiva, espera-se observar particularidades entre as escolas. Assim, a partir das reflexões, aferiu-se que as diferentes visões acerca da dinâmica das decisões de investimento - mesmo inseridas em um mesmo programa de pesquisa, o pós-clássico denotam a complexidade dessa variável.

Palavras-chave: Investimento. pós-keynesianos. kaleckianos.

Classificação JEL: E22; E12; E19.

\footnotetext{
Agradecemos os comentários e sugestões do Professor Dr. André Luiz Cabral de Lourenço - UFRN, eximindo-o, naturalmente, de possíveis equívocos remanescentes.

2 Bacharel em Economia pela Universidade Federal do Rio Grande do Norte (UFRN). Mestre em Economia (PPEGO/ UFRN).Email: jonilsonufrn@yahoo.com.br

3 Graduada em Licenciatura Plena em Geografia pelo Instituto Federal de Educação, Ciência e Tecnologia do Rio Grande do Norte (IFRN) e mestranda pelo Programa de Pós-Graduação em Geografia da Universidade Federal do Rio Grande do Norte. Email: susilva_oi@yahoo.com.br
} 


\section{INTRODUÇÃO}

A literatura econômica, em sentido amplo, é envolvida empiricamente pelos processos de escolha inerentes aos agentes econômicos. Esse mecanismo, implicitamente, traz consigo questões típicas da atividade alocativa, tais como: o que? Como? Por quanto? Onde? As quais independentemente da esfera, produtiva ou financeira, devem ser apreciadas cuidadosamente.

Nesse sentido, o presente artigo objetiva suscitar reflexões teóricas, de caráter preliminar, acerca de uma das variáveis fundamentais do escopo macroeconômico: o investimento. ${ }^{4}$ Inserido comumente em um contexto interligado entre o circuito produtivo e o circuito financeiro, via taxa de juros ${ }^{5}$, o investimento, intrinsecamente, denota o processo recorrente da decisão de alocação entre ativos produtivos (bens de capital) e ativos financeiros (caderneta de poupança, ações, títulos públicos, entre outros).

Enquanto o investimento significa expansão da capacidade produtiva, a qual gera uma expectativa de rentabilidade que pode ou não se efetivar em lucros, a aplicação é a alocação dos recursos em atividade especulativa, a qual pode se converter em juros (remuneração da riqueza aplicada), a depender do rendimento das aplicações. Esta é uma forma simplificada de tratar a questão, i.e, a alocação de bens de capital compete, por assim dizer, com "n" outros ativos financeiros (DAVIDSON, 1994).

Tal como a decisão de investir ou aplicar, a discussão da relação entre poupança e investimento, a qual deriva da decisão de consumir de imediato ou consumir em um período futuro, também permeia as reflexões acerca do investimento na economia capitalista contemporânea. Contudo, dada a natureza complexa e multifacetária, o escopo do artigo se limita a analisar o investimento a partir do programa de pesquisa heterodoxo.

Contrariamente ao programa neoclássico (ortodoxo), vinculado a Lei de Say no longo prazo, o programa heterodoxo, analisa a economia a partir do Princípio da Demanda Efetiva. Trata-se de recuperar a questão da autonomia relativa do capitalista, onde suas decisões econômicas devem considerar a necessidade de venda de suas mercadorias, tendo em vista que ele não pode decidir que sua mercadoria será comprada.

Ver: Possas (1999, p. 31) e Minsky (1986, p. 174).

Para além dessa razão, há outras como as condições de crédito, o valor das ações e o grau de endividamento. 
Nesse sentido, Possas (1987, p. 51) afirma que "Em qualquer ato de compra e venda tomado isoladamente, produz-se um fluxo monetário pagamento de um lado, recebimento de outro - decorrente de uma única decisão autônoma: a de efetuar determinado dispêndio". Assim, o cuidado do capitalista com aspectos como qualidade, propaganda, níveis de preço e quantidade oferecidos não assegura a venda de sua mercadoria, visto que apenas as decisões de gasto determinam a geração do fluxo de riqueza nova na sociedade, a demanda efetiva.

Dito isso, o presente ensaio desenvolve um exame preliminar dos determinantes do investimento, partindo de uma leitura de duas vertentes: Pós-keynesianos (fundamentalistas) e Kaleckianos. ${ }^{6}$ Utilizando uma metodologia estritamente bibliográfica, questiona: há diferenças teóricas entre os modelos de investimento, Pós-keynesiano em face ao kaleckiano? A hipótese proposta é que mesmo sendo de natureza heterodoxa, apresentam em entre si, particularidades não negligenciáveis.

Para tanto, o ensaio segue organizado em três seções, além da introdução. Descreve-se a vertente kaleckiana, imbuída da Teoria da Dinâmica Econômica (1954), na seção dois. Na seção três apresenta-se a leitura dos pós-keynesianos, sob o marco referencial da Teoria Geral do Emprego, do Juro e da Moeda (1936). E, finalmente, na seção quatro, tecem-se algumas considerações acerca das confluências e limitações das vertentes apreciadas.

\section{OS DETERMINANTES DO INVESTIMENTO NA VISÃO KA- LECKIANA}

Michal Kalecki, teórico de formação marxista e seguidor do Princípio da Demanda Efetiva, desenvolve uma teoria para as decisões de investimento, sistematizando o que, costumeiramente, o senso comum expressa: "ganha dinheiro quem tem dinheiro". ${ }^{7}$ Contrariando os que supõem apenas a existência de habilidades empresarias, expõe a propriedade do capital - a partir dos lucros recorrentes - como o pré-requisito fundamental para o ato de investir, inclusive no caso das sociedades anônimas (KALECKI, 1954, p. 113).

\footnotetext{
Uma terceira vertente heterodoxa, dado o escopo do trabalho, foi negligenciada, a sraffiana.

Para uma leitura marxista do princípio da demanda efetiva, incluindo uma análise dos determinantes dos investimentos ver Miglioli (1982).
} 
As tentativas de formular uma teoria empiricamente consistente para o investimento em capital fixo são presentes nas obras de Kalecki desde 1933, na qual, passando por modificações - agregando ou abandonando variáveis - apresenta uma modelagem mais acabada em $1954 .^{8}$ De modo que a presente leitura limita-se a descrição dessa última, onde o capital acumulado das firmas e o consequente acesso ao crédito são fatores estratégicos. ${ }^{9}$

Uma das inovações do modelo acabado se refere ao hiato temporal, $\tau$, de modo que este passa a referir-se, conforme Kalecki (1954, p. 117), "em grande parte ao período de construção, mas também reflete fatores como decisões empresariais retardadas". Assim, de maneira breve, priorizando as implicações teóricas dos seus componentes, segue a apresentação da equação dos determinantes do investimento em Kalecki. Tecnicamente:

$$
\mathrm{F}_{\mathrm{t}+\tau}=\mathrm{aS}_{\mathrm{t}}+\mathrm{b} \frac{\Delta \mathrm{P}_{\mathrm{t}}}{\Delta \mathrm{t}}-\mathrm{c} \frac{\Delta \mathrm{K}_{\mathrm{t}}}{\Delta \mathrm{t}}+\mathrm{d}
$$

A análise visual da equação 1, traduz o caráter da decisão de investimento por unidade de tempo requerida por Kalecki. Onde o investimento em capital fixo, $F$, em uma primeira aproximação linear, será explicado junto aos respectivos coeficientes ${ }^{10}$ - diretamente pela poupança bruta, $S$, e pela taxa de modificação do montante dos lucros, $P$; e inversamente, pela taxa de variação do estoque de capital em equipamento, $K$. Completando as variáveis independentes, tem-se a absorção dos efeitos das decisões autônomas de investimento, $d$.

Kalecki, utilizando as variáveis deflacionadas pelo índice de preços dos bens de capital, sugere - sob a tentativa de explicar as crises que se acentuavam - uma análise real da economia. E, ao propor o modelo por unidade de tempo, acaba por tornar as teorias de investimento do ciclo econômico

\footnotetext{
Na verdade, Kalecki escreveu trabalhos posteriores sobre essa teoria, pois a vida toda ele permaneceu insatisfeitos com seus trabalhos sobre esse tema. Há, contudo, razões para acreditar que essa versão de 1954 capta melhor a essência da sua contribuição (POSSAS, 1987).

9 Dois outros fatores são refutados, por Kalecki, como limitantes do crescimento das firmas: as deseconomias de grande escala e o mercado, este último de maneira menos contundente. (KALECKI, 1954, p. II3).

10 Por convenção teórica, os parâmetros a, b e c são maiores que 0 , sendo que a, supõe-se ser também menor que um e, portanto, $(0<a<1)$ (POSSAS, 1987, p. 126)
} 
e do princípio da aceleração como casos particulares da sua teoria, que considera mais consistente empiricamente (KALECKI, 1954, p. 120-124).

Analisando teoricamente a equação e, segundo Possas (1987, p. 125128), o termo $\mathrm{aS}_{\mathrm{t}}$, denota uma simplificação do modelo, pois ao utilizar a poupança bruta corrente como proxy da acumulação interna das empresas, absorve os efeitos da obtenção de fundos externos para financiar os investimentos, bem como o risco financeiro crescente $^{11}$ enfrentado pelo capitalista ao reinvestir seu patrimônio na expansão da produção, no contexto de mercado limitado. ${ }^{12}$

Conforme Kalecki (1954), outro fator estratégico na taxa de decisões de investimento é a taxa de variação dos lucros esperados pela decisão de investir, expressa conjuntamente pelos dois termos seguintes da equação 1, os quais, nas palavras de Possas (1987, p. 130), refletem "variações no nível de atividade vis-à-vis da capacidade instalada", pois, tendo por hipótese, mark ups estáveis, o impacto cíclico no modelo se deve às flutuações de demanda.

O último componente, o termo d, de tímida atenção dispensada pelo autor, representa os componentes relativamente autônomos - os fatores do desenvolvimento - particularmente aqueles relacionados ao progresso tecnológico, ${ }^{13}$ os quais explicam o investimento, mesmo em circunstâncias de capacidade ociosa, dada a obsolescência do capital, a qual gera uma depreciação maior, e, por conseguinte, maior investimento (POSSAS, 1987, p. 131).

Sintetizando a proposta kaleckiana, a taxa das decisões de investimento em capital fixo, em ma economia capitalista desenvolvida, é determinada pelo capital disponível dos capitalistas (estes ganham o que gastam), pelo hiato entre o investimento efetivo e o necessário (ajuste cíclico das decisões) e pela influência das inovações. De modo que, este modelo, por vezes é interpretado como uma leitura particular da teoria de Keynes, objeto da seção seguinte.

' Esse conceito, inicialmente utilizado por Kalecki, estará absorvido pelas ideias de Keynes quando este se refere à curva de demanda por investimento. (KEYNES, 1936, p. 150).

12 Se expressa aqui a validade do Princípio da Demanda Efetiva no Longo prazo, que em contraposição a Lei de Say, exprime a demanda como fator limitante da produção e, portanto, de desestimulo ao investimento adicional. Assim, a inclusão desse termo agrega o caráter instável e dinâmico da atividade econômica, proporcionando uma vantagem modelística de Kalecki frente ao "acelerador" convencional (POSSAS, 1987).

13 Para maiores elucidações a respeito, ver: Kalecki (1954, p. I84- | 85). 


\section{OS DETERMINANTES DO INVESTIMENTO NOS PÓS-KEY- NESIANOS}

John Maynard Keynes apresenta uma teoria de investimento em capital fixo onde as expectativas assumem papel fundamental na decisão de alocar os recursos. Ao estabelecer um modelo de escolha de portfólio, diferentemente da proposta de Kalecki, ele determina a variável taxa de juros como estratégica e explícita no modelo, ligando-o a esfera monetária.

Assim como o modelo kaleckiano, a teoria das decisões de investimento em Keynes emerge no contexto da necessidade de elementos alternativos para explicação das crises, em particular, a depressão de 1930. Nesse contexto, a Teoria Geral sugere dois modelos ${ }^{14}$ (distintos quanto à taxa de juros), o primeiro, adotando um título genérico e, portanto, simplificado, e o segundo, estabelecido a partir de um portfólio de ativos. Em ambos, explicita o confronto da taxa de juros com a expectativa do retorno esperado do investimento.

A abordagem das expectativas representa uma ruptura com os postulados neoclássicos. Ao demonstrar a incerteza da renda sobre a qual o investimento se sustenta, traduzida na eficiência marginal do capital $(\mathrm{EMgK})$ - proxy da taxa de lucro esperada -, Keynes denota a possibilidade da existência de capacidade ociosa, consequência da demanda efetiva limitada, se contrapondo ao desenhado pelo mundo neoclássico (KEYNES, 1936, p. 149-151).

Portanto, conforme Keynes (1936, p. 150), a decisão de investimento dependerá tanto da avaliação da EMgK - implicitamente, da demanda agregada de curto prazo e a oferta agregada de longo prazo -, quanto da taxa de juros. ${ }^{15}$ Sendo esta última um fenômeno corrente, a expectativa acerca da renda (sujeita a flutuações), explicaria o caráter cíclico da economia e, via utilização de um bem durável, criaria um elo do presente com o futuro.

Nesse contexto, surgem os pós-keynesianos, que como ressalta Lima (1992, p. 97), sob a tutela de "atualizar e dar continuidade ao projeto teórico [...] concebido.” A importância da incerteza e das expectativas nas posições

\footnotetext{
14 Trata-se de teorias um pouco diferentes entre si. Enquanto a primeira, no capitulo I I da TG, analisa a decisão de investimento supondo um contexto de equilíbrio parcial, a do capítulo I 7 desenvolve uma comparação do retorno esperado do investimento com o de " $n$ " outros ativos de diversos tipos (KEYNES, 1936).

15 Um debate ampliado acerca dessa relação é obtido a partir da "statistical ogive" (DAVIDSON, 1994, p. 63).
} 
de equilíbrio de longo prazo, tanto na economia real como na monetária é reiterada. Assim, a leitura aos Keynesianos a partir dos neoclássicos teria descaracterizado a proposta original de Keynes, a qual precisaria ser recuperada. ${ }^{16}$

Posto isso, a decisão de investir, e, por conseguinte, de demandar financiamento, exigira do capitalista - além das expectativas acerca dos atributos dos bens duráveis (quase-renda, prêmio de liquidez, custo de estocagem, variação do preço do ativo) ${ }^{17}$ e da volatilidade do mercado monetário - Minsky (1986, p. 171) ressalta o conhecimento dos desdobramentos das flutuações recorrentes nos mercados, produtivo e financeiro, nas expectativas dos agentes.

De modo que, embora mantidas as origens, a lógica proposta pelos pós-keynesianos "fundamentalistas" transpõe o foco da análise da eficiência marginal para o mercado de bens de capital - supõe-se que o sistema de preços traduza as flutuações nas expectativas dos capitalistas, quanto aos lucros esperados - e para o mercado financeiro, ambos propensos ao risco e a incerteza, refletidos também nas taxas de juros.

Nesse contexto, merece destaque o modelo de Minsky, o qual sugere que na decisão de investimento a disponibilidade de financiamento externo (à empresa) é o elemento-chave. Neste modelo há três posturas financeiras do agente em relação ao risco de mudança da taxa de juros: i) hedge: espera ser capaz de pagar tanto o principal quanto os juros de sua dívida, de modo que não seja necessário refinanciamento e assim a divida líquida decresça; ii) especulativas: não espera ser capaz de pagar o principal, mas apenas os juros da dívida, ao passo que pela necessidade de refinanciado parcial, a dívida líquida mantenha-se estável; e, iii) Ponzi: não espera ser capaz de pagar nem o principal, nem os juros integralmente, e consequentemente, a dívida líquida será crescente (MISNKY, 1986).

Contudo, considerando os objetivos e limites do presente ensaio, o modelo adotado para representar a vertente pós-keynesiana em tela é uma formulação de Davidson. Embora sua contribuição não tenha captado ade-

\footnotetext{
16 Trata-se da síntese neoclássico-keynesiana. A Hicks, com o ensaio "Mr. Keynes and The Classics", de 1937, comumente atribui-se o "berço" do Modelo IS-LM - a mais famosa e influente interpretação de Keynes. Ele é uma visão equilibrista da Teoria Geral, isto é, uma tentativa de mediação teórica entre modelos estáticos e dinâmicos, na medida em que aponta as mudanças/ciclos como sendo equilíbrios temporários/parciais. Consiste na determinação do nível de renda e a taxa de juros de equilíbrio em uma economia fechada, os quais equilibram simultaneamente o mercado de bens (curva IS) e o mercado monetário (curva LM).

17 Para aprofundar a discussão acerca desses atributos, ver Davidson (1994, p. 54-56).
} 
quadamente um elemento fundamental ${ }^{18}$, baseando-se no capitulo $17 \mathrm{da}$ Teoria Geral, ele obtém uma teoria do investimento que, embora em formato diferente e mais rico, preserva as contribuições de Keynes e as capta de forma melhor do que a versão de manual.

Assim, ele aponta que no mercado de bens de capital, enquanto a demanda por estoque, $\mathrm{D}_{\mathrm{k}}$, é determinada pelo seu preço de mercado, $\mathrm{P}_{\mathrm{k}}$; pela taxa de desconto, i; pelas expectativas em relação a demanda e o fluxo de quase-renda esperado, $\Phi$; e pelo número de empresários que obtêm financiamento para demandá-los, E; a oferta de estoque de capital, $S_{k}$, responderá ao preço do bem, $\mathrm{P}_{\mathrm{k}}-$ sendo $S_{k}$, a inelasticidade-preço e $S_{k}$ a elasticidade-preco - o qual, dentre outros fatores, reflete a estrutura de custos marginais crescentes e o grau médio de monopólio dos produtores; finalmente, a presença de termos, $\mathrm{d}_{\mathrm{k}}$ e $\mathrm{s}_{\mathrm{k}}$, respectivamente os fluxos de demanda e oferta nas equações, completam o modelo (DAVIDSON, 1994, p. 57-61). Formalmente:

$$
\begin{gathered}
D_{k}+d_{k}=f\left(P_{k}, i, \phi, E\right) \\
D_{k}+d_{k}=f\left(P_{k}\right) \\
\left(D_{k}+d_{k}\right)-\left(S_{k}+s_{k}\right)=0
\end{gathered}
$$

Como expresso na equação 4, em cada período os produtores tendem ao equilíbrio, uma vez equiparado o fluxo de demanda com o fluxo de oferta de bens de capital. No entanto, os mecanismos endógenos que condicionam os chamados "períodos de tranquilidade", permanecem atuando, e, portanto, desequilibrando o mercado, carregando a economia - dada sua natureza financeira - para um boom especulativo.

Posto isso, a liquidez emerge como atributo essencial do ativo, seja ele real ou financeiro. E, na medida em que a discussão das fontes de financiamento externo adquire status nas decisões de investimento, os mercados (produtivo e financeiro), passam a ser analisados conjuntamente, aspecto factível a construção de um modelo de dois preços interligados, os quais respondem a fatores expectacionais.

18 Trata-se da ideia de que em um ambiente de decisão que envolve várias alternativas de ativos, a ampliação da participação de qualquer um deles amplia o risco. 
Isso posto, apresentados sinteticamente os determinantes das decisões de investimento em Keynes e nos fundamentalistas, afere-se que estes se concentram em demonstrar a instabilidade inerente a economia capitalista, a qual, embora políticas anticíclicas possam ser utilizadas, seus efeitos estabilizadores são apenas temporários, de modo que sua dinâmica não pode ser extraída, dado que o capitalismo seria "vocacionado" à crises.

\section{CONSIDERAÇÕES FINAIS}

A exposição das seções anteriores afere que tanto em Keynes quanto em Kalecki, o efeito causalidade entre investimento e poupança difere da proposta convencional. E, dadas as possibilidades de financiamento, o investimento se configura como uma variável ex ante ao processo de produção, o qual tende a gerar poupança, que, por conseguinte, é um variável ex post da atividade produtiva.

No modelo kaleckiano, observam-se algumas lacunas quando comparado com a proposta de Keynes, tais como: o papel secundário da taxa de juros e das expectativas, o que, segundo o autor, em face da simplificação, tais efeitos são absorvidos implicitamente. Apesar da justificativa, dados os aspectos teóricos insuficientes, uma leitura "descuidada" do modelo, predispõe o leitor a alguns conflitos. ${ }^{19}$ Por outro lado, sua discussão de ciclo é diferenciada.

Pelo relativo rigor teórico-conceitual, a leitura de Keynes é vista como mais geral e de maior facilidade quanto ao relacionamento do investimento com os ciclos econômicos frente a proposta de Kalecki. No entanto, ao explicar a crise como uma consequência de falhas nas expectativas e, por conseguinte, um fenômeno de natureza humana, ele superestima o subjetivo e negligencia as leis objetivas da economia.

Em síntese, em face do objetivo do presente artigo, os dois modelos apresentados se confirmaram como marco teórico na literatura econômica. E, mesmo apresentando algumas particularidades, condição sine qua non ao desenvolvimento cientifico, não se refutam. Do contrário, as concepções se mostram próximas, e por que não dizer, complementares.

\footnotetext{
19 Sendo uma das importantes contribuições kaleckianas a ruptura radical com a doutrina defensora da poupança como precedente e condicionante do investimento, Kalecki, ao explicitar o investimento como função do período anterior acaba gerando uma contradição analítica.
} 


\section{THEORIES OF INVESTMENT: A PRELIMINARY READING OF POST-KEYNESIANS AND KALECKIANS}

\section{Abstract}

Accepting the importance of investment in the macroeconomic debate, this paper proposes a preliminary analysis of the determinants of private investment decisions in two approaches of the heterodoxy: the Post-Keynesians and Kaleckian. Using a theoretical literature based on demand side, the main question is: are there differences, in the theoretical perspective, between the two models? Although both approaches are guided by the Principle of Effective Demand, differences are observed between schools. Different views about the dynamics of investment decisions - even inserted in the heterodox post-classical research program - denote the complexity of this variable.

Keywords: Investment. Post-keynesians.Kaleckians.

JEL Classification: E22; E12; E19.

\section{REFERÊNCIAS}

DAVIDSON, P. Post Keynesian Macroeconomic Theory. Aldershot: Edward Elgar, 1994.

HICKS, J.R. O Sr. Keynes e os clássicos: uma sugestão de interpretação. In: Clássicos de literatura econômica. Rio de Janeiro: IPEA/INPES, 1988.

KALECKI, M. (1954). Teoria da Dinâmica Econômica. (coleção os Economistas). Tradução de Leônidas de Carvalho. São Paulo: Nova Cultural, 1988.

KEYNES, J. M. (1936). A teoria Geral do Emprego do Juro e da Moeda. (coleção os Economistas). Tradução de Mário R. da Cruz. São Paulo: Nova Cultural, 1988. 
LIMA, G.T. Em Busca do Tempo Perdido: A Recuperação Pós-Keynesiana da Economia do Emprego de Keynes. Rio de Janeiro: BNDES, Prêmio BNDES, 1992.

MIGLIOLI, Jorge. Acumulação de Capital e Demanda Efetiva. São Paulo: T.A. Queiroz, 1985.

MINSKY, H.P. Stabilizing an Unstable Economy. New Haven: Yale University Press, 1986.

POSSAS, M.L. Dinâmica da Economia Capitalista: uma Abordagem Teórica. São Paulo: Brasiliense, 1987.

- Demanda Efetiva, Investimento e Dinâmica: a atualidade de Kalecki para a Teoria Macroeconômica. Revista de Economia Contemporânea. vol. 3, jul./dez. 1999. 